\title{
Comparison of the suitability of alkaline or enzymatic sample pre-treatment for characterization of silver nanoparticles in human tissue by single particle ICP-MS
}

\author{
Vidmar, Janja; Buerki-Thurnherr, Tina; Löschner, Katrin
}

Published in:

Journal of Analytical Atomic Spectrometry

Link to article, DOI:

10.1039/C7JA00402H

Publication date:

2018

Document Version

Peer reviewed version

Link back to DTU Orbit

Citation (APA):

Vidmar, J., Buerki-Thurnherr, T., \& Löschner, K. (2018). Comparison of the suitability of alkaline or enzymatic sample pre-treatment for characterization of silver nanoparticles in human tissue by single particle ICP-MS. Journal of Analytical Atomic Spectrometry, 33, 752-761. https://doi.org/10.1039/C7JA00402H

\section{General rights}

Copyright and moral rights for the publications made accessible in the public portal are retained by the authors and/or other copyright owners and it is a condition of accessing publications that users recognise and abide by the legal requirements associated with these rights.

- Users may download and print one copy of any publication from the public portal for the purpose of private study or research.

- You may not further distribute the material or use it for any profit-making activity or commercial gain

- You may freely distribute the URL identifying the publication in the public portal 

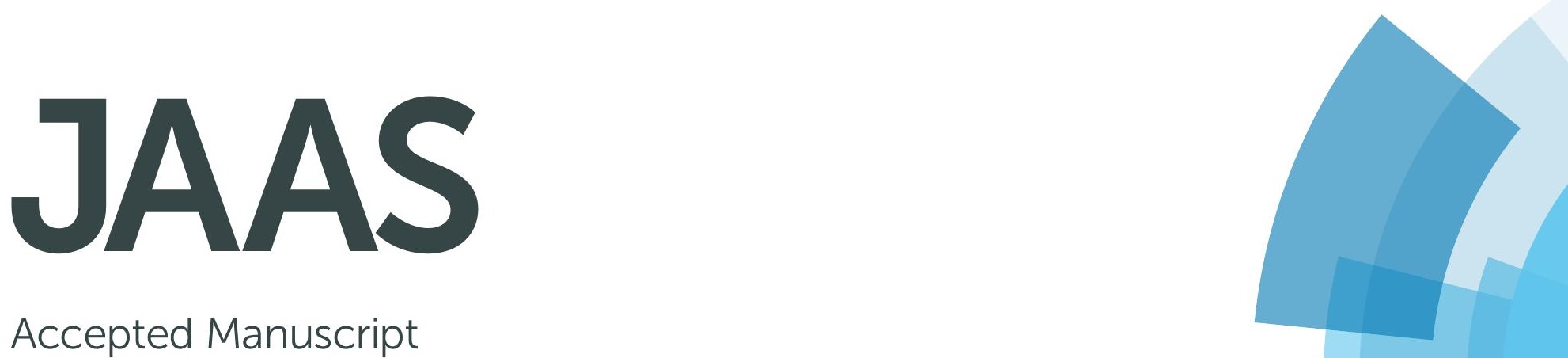

\section{Accepted Manuscript}

This article can be cited before page numbers have been issued, to do this please use: J. Vidmar, T. Buerki-Thurnherr and K. Loeschner, J. Anal. At. Spectrom., 2018, DOI: 10.1039/C7JA00402H.

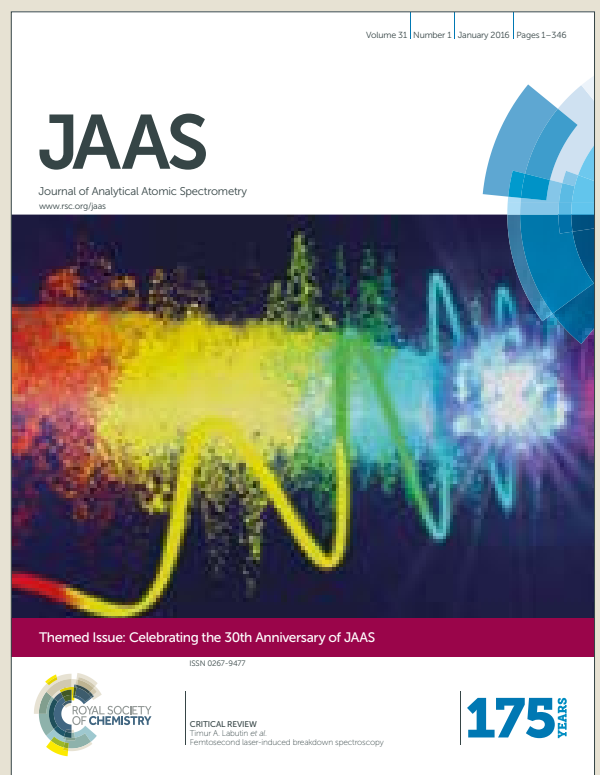

This is an Accepted Manuscript, which has been through the Royal Society of Chemistry peer review process and has been accepted for publication.

Accepted Manuscripts are published online shortly after acceptance, before technical editing, formatting and proof reading. Using this free service, authors can make their results available to the community, in citable form, before we publish the edited article. We will replace this Accepted Manuscript with the edited and formatted Advance Article as soon as it is available.

You can find more information about Accepted Manuscripts in the author guidelines.

Please note that technical editing may introduce minor changes to the text and/or graphics, which may alter content. The journal's standard Terms \& Conditions and the ethical guidelines, outlined in our author and reviewer resource centre, still apply. In no event shall the Royal Society of Chemistry be held responsible for any errors or omissions in this Accepted Manuscript or any consequences arising from the use of any information it contains. 
 \\ Comparison of the suitability of alkaline or enzymatic sample pre-treatment for characterization of silver nanoparticles in human tissue by single particle ICP-MS
}

\author{
Janja Vidmar, ${ }^{\mathrm{a}, \mathrm{b}}$ Tina Buerki-Thurnherr, ${ }^{\mathrm{c}}$ Katrin Loeschner* ${ }^{\mathrm{d}}$ \\ ${ }^{a}$ Department of Environmental Sciences, Jožef Stefan Institute, Jamova 39, 1000 Ljubljana, Slovenia \\ ${ }^{b} J o \check{e}$ e Stefan International Postgraduate School, Jamova 39, 1000 Ljubljana, Slovenia \\ ${ }^{c}$ Particles-Biology Interactions, Empa, Swiss Federal Laboratories for Materials Science and Technology, \\ Lerchenfeldstrasse 5, 9014 St. Gallen, Switzerland \\ ${ }^{d}$ Division for Food Technology, National Food Institute, Technical University of Denmark, Kemitorvet 201, DK-2800 \\ Kgs. Lyngby, Denmark \\ *Corresponding author: \\ Katrin Loeschner \\ Phone: +4535887029 \\ Fax: +4535887448 \\ Email: kals@,food.dtu.dk
}

To understand potential harmful effects of silver nanoparticles (AgNPs) for the growing fetus, studies dealing with the translocation and accumulation of NPs across placental barrier are of great importance. Quantitative methods for determination of NP mass and number concentration and their size are required for studying NP accumulation in placental tissue. In the present study, we applied and compared two sample preparation techniques, alkaline and enzymatic treatment, followed by single particle ICP-MS (spICP-MS) analysis, for characterizing AgNPs spiked to human placental tissue. Both sample preparation approaches are currently used for AgNPs in biological tissues but have not been directly compared yet. We showed that the method using enzymatic tissue treatment followed by spICP-MS is efficient for determination of mass and number concentration and size distribution of AgNPs in human placental tissues. Properties of the AgNPs were preserved during enzymatic digestion and comparable with the primary particles. The matrix effect on the determination of $\mathrm{Ag}$ sensitivity and transport efficiency in spICP-MS analysis was systematically evaluated as well. The method was applied to human placenta, exposed to AgNPs with two different surface modifications: $27 \mathrm{~nm}$ polyethylene glycol (AgPEG NPs) or $34 \mathrm{~nm}$ sodium carboxylate groups (AgCOONa NPs) in an ex vivo human placental perfusion model. The Ag mass concentration obtained with spICP-MS following enzymatic sample pretreatment was not significantly different from the Ag concentration obtained by conventional ICP-MS analysis of acid digested tissue. With this we confirmed 
the ability of the procedure to quantitatively characterize AgNPs accumulated in human tissue under realistic exposure scenario.

Keywords silver nanoparticles, single particle ICP-MS, sample preparation, alkaline treatment, enzymatic treatment, human placenta tissue

\section{Introduction}

The significant rise in consumer products and applications utilizing the antibacterial properties of silver nanoparticles (AgNPs) (e.g. food contact materials, textile, laundry detergents, dietary supplements, cosmetics, nose and eye drops) has increased the possibility of human (i.e. oral, dermal, mucosal) exposure to Ag. ${ }^{1}$ Due to specific properties of AgNPs (i.e. small size and high reactivity) they can cross biological membranes and barriers, e.g. the placental barrier, posing risks to the growing fetus. ${ }^{2-8}$ To obtain predictive results, the uptake and accumulation of NPs should be studied in human placental tissue since the placenta is the most species-specific organ. ${ }^{9}$ The ex vivo dual recirculating human placental perfusion provides an excellent model to study the transfer of xenobiotics and particles at term pregnancy. In this model, human placental tissue obtained after caesarean section is cannulated from the maternal and fetal side, placed into a perfusion chamber and connected to peristaltic pumps to establish individual maternal and fetal circulations. NPs are added to the maternal circulation and translocation to the fetal side is measured up to 4-6 $\mathrm{h}$ of perfusion. ${ }^{10-12}$

In order to investigate the degree of NP accumulation in biological tissue and the influence of different characteristics of NPs on their uptake, suitable analytical methods, that release NPs from tissues and enable their detection, quantification and characterization, are required. Since the toxicity of AgNPs is related to the presence of $\mathrm{Ag}$ ions $\left(\mathrm{Ag}^{+}\right)$that are released from the AgNPs by dissolution ${ }^{13-16}$ the methods should be able to selectively determine AgNPs and Ag ions as well. Frequently used methods for NPs characterization and quantification are scanning and transmission electron microscopy (SEM / TEM), light scattering (e.g. dynamic light scattering (DLS), nanoparticle tracking analysis (NTA)) or separation techniques, including field flow fractionation (FFF) and hydrodynamic chromatography (HDC). ${ }^{17}$ The latter are most commonly coupled to inductively coupled plasma-mass spectrometry (ICP-MS) for highly sensitive and element specific detection. ICP-MS can be also combined with laser ablation (LA-ICP-MS) that images localization of NPs in tissues. ${ }^{18,19}$ However, none of the methods mentioned are able to simultaneously differentiate the form of a measured analyte (i.e. ionic or particulate metal) and to determine the size distribution and aggregation state of NPs. Moreover, most of them require sample preparation techniques that can change the physicochemical properties of NPs, thus introducing artefacts in their analysis.

One of the most promising methods for the determination of particle mass/number concentration and size distribution is the relatively novel analytical technique single particle ICP-MS (spICP-MS). SpICP-MS is a fast, very sensitive ( $\mathrm{ng} / \mathrm{L}$ concentration range) and particle number-based technique that ensures simultaneous characterization of metal in the nanoparticle and the ionic form. ${ }^{20}$ While only simple dilution is 
required when aqueous samples are measured by spICP-MS, NPs in biological tissues need to be released from the matrix, preferably without altering their properties. NPs in tissues are generally quantified based on the mass concentrations of the analyte measured after acid digestion of the samples, which leads to dissolution of most NPs. Alkaline solubilization, most commonly used with tetramethylammonium hydroxide (TMAH), was, on the other hand, found to be effective for releasing NPs from the tissues of Daphnia magna and Lumbriculus variegatus (AgNPs, AuNPs), ${ }^{21}$ tissue and feces of rats (AgNPs, AuNPs), ${ }^{19,22}$ ground beef (AgNPs, AuNPs), ${ }^{21}$ human hepatoma (HepG2) cells (AgNPs) ${ }^{13}$ and primary human endothelial cells (AuNPs). ${ }^{23}$ In a similar way, enzymatic treatment with the use of proteases has been applied for extracting NPs from the tissues of rats (AgNPs, AuNPs), ${ }^{22,24}$ earthworms (AgNPs), ${ }^{25}$ chicken meat (AgNPs), ${ }^{26-29}$ game meat $(\mathrm{Pb}),{ }^{30}$ eff yolk (AgNPs) ${ }^{31}$ and human synovial fluid $(\mathrm{Cr}, \mathrm{Co}) .{ }^{32}$ Macerozyme R-10, a mixture of pectinase, cellulase and hemicellulase, has been applied for NPs in plants, e.g. shoots of tomato plants (AuNPs), ${ }^{33}$ Lepidium sativum and Sinapis alba (PtNPs), ${ }^{34}$ shoots of cucumber, tomato, soybean and pumpkin plants $\left(\mathrm{CeO}_{2} \mathrm{NPs}\right)^{35}$ and roots and shoots of Arabidopsis thaliana plants (AgNPs). ${ }^{36}$

However, sample preparation techniques that digest or solubilize the biological tissues without altering the AgNPs are still limited. A direct comparison of alkaline and enzymatic sample preparation methods followed by spICP-MS analysis has not been published yet and has not been applied for detection, characterization and quantification of NPs in human tissues. Moreover, most of the studies, where spICPMS was used for quantification and characterization of AgNPs after their extraction from different tissue types, did not investigate the influence of potential matrix effects on NPs size calibration. ${ }^{21,26,29}$

The objectives of this study were to: 1) investigate matrix-matching of calibration standards for AgNPs sizing by spICP-MS and 2) compare the two potentially suitable sample preparation methods, alkaline treatment with the use of the strong base TMAH and enzymatic treatment with the use of the stable and highly active enzyme Proteinase K, for releasing two types of AgNPs from human placental tissue. Since AgNPs are soluble, one aspect was to distinguish between ionic and particulate Ag. The most appropriate treatment process was then applied for quantification and characterization of AgNPs accumulated in human placenta in the ex vivo human placental perfusion model.

\section{Experimental}

\section{Human placenta tissue samples}

Placentas were obtained from uncomplicated term pregnancies after caesarean section at the Cantonal Hospital or Klinik Stephanshorn in St.Gallen, Switzerland. Written informed consent was obtained prior to delivery. The project was approved by the local ethics committee and performed in accordance with the principles of the Declaration of Helsinki. The placenta perfusion experiments were performed on a human ex vivo placenta perfusion model at Swiss Federal Laboratories for Materials Science and Technology (Empa) 
as described previously. ${ }^{37,38}$ Perfusion experiments were started by adding $12.48 \mathrm{mg} / \mathrm{L}$ of $\mathrm{DAg}^{10} \mathrm{PPEG} / \mathrm{C}$ or $30402 \mathrm{H}$ $\mathrm{mg} / \mathrm{L}$ of $\mathrm{AgCOONa}$ NPs into the maternal circulation. The concentration values are based on conventional ICP-MS measurements of acid digested perfusion samples, collected at time 0h (before the start of perfusion). The results of this study will be published elsewhere. Placenta tissue from the villous chorion was collected before $(0 \mathrm{~h})$ and after each perfusion experiment (after $6 \mathrm{~h}$ ), frozen and stored for maximum 2 months at $-20^{\circ} \mathrm{C}$. The thawed tissue was homogenized using a TissueRuptor (Qiagen, Hombrechtikon, Switzerland) by mixing $2 \mathrm{~g}$ of tissue in $2 \mathrm{~mL}$ of perfusion buffer for 30s (dilution factor of 2). Sodium azide at a concentration of $200 \mathrm{mg} / \mathrm{L}$ was added to the homogenates to avoid bacterial growth. Homogenates were shipped from Switzerland to Denmark at $4{ }^{\circ} \mathrm{C}$ and further stored at $-20^{\circ} \mathrm{C}$. In order to test possible particle formation from $\mathrm{Ag}$ ions perfusion with $1 \mathrm{mg} / \mathrm{L}$ of ionic $\mathrm{Ag}$ was performed. Perfusion with perfusion medium was performed to determine the Ag background level.

\section{Chemicals}

Ultrapure water (UPW; resistivity $18.2 \mathrm{~m} \Omega . \mathrm{cm}$ ) was obtained from a Millipore Element apparatus (Millipore, Milford, MA, USA) and used throughout the work. ReagentPlus sodium dodecyl sulphate (SDS) with $\geq 98.5 \%$ purity, ammonium bicarbonate with $99 \%$ purity and sodium azide with $\geq 98 \%$ purity were purchased from Sigma-Aldrich (St. Louis, MO, USA). For the enzymatic digestion the commercial protease Proteinase K from Engyodontium album was used (Sigma-Aldrich St. Louis, MO, USA). Proteinase K is a serine protease with a molecular mass of $28930 \mathrm{~g} / \mathrm{mol}$, a broad $\mathrm{pH}$ range of $7.5-12$ and a temperature optimum of $37^{\circ} \mathrm{C}$ regarding the enzyme activity. For the alkaline solublization TMAH $(25 \% \mathrm{v} / \mathrm{v})$ obtained from Alfa Aesar (Ward Hill, MA, USA) was used. Nitric acid (67-69\%) and hydrochloric acid (34-37\%) of PlasmaPURE quality (SCP Science, Baie D'Urfé, QC, Canada) and Triton X-100 (Merck, Darmstadt, Germany) were used for rinsing of the ICP-MS system between each sample. PlasmaCAL standards of Ag and $\mathrm{Au}$ at $1000 \mu \mathrm{g} / \mathrm{mL}$ for spICP-MS analysis were obtained from SCP Science (Baie D'Urfé, QC, Canada). For digestions of tissues, nitric acid (65\%) and hydrochloric acid (30\%) supplied by Merck Millipore (Milford, MA, USA) were used. Calibration standard solutions for quantification of Ag in the tissues by conventional ICP-MS were prepared from an Ag stock solution obtained from Merck (Darmstadt, Germany). For determination of the transport efficiency for spICP-MS a reference material gold nanoparticle (AuNP) suspension at $30 \mathrm{~nm}$ in nominal diameter (RM8012) was obtained from the National Institute for Science and Technology, NIST (Gaithersburg, MD, USA). As positive control for the validation of spICP-MS method, $40 \mathrm{~nm}$ NanoXact Silver Nanospheres with PEG surface functionalization were purchased from Nanocomposix (San Diego, CA, USA). According to the provided data sheet, the particle diameter was $40 \pm 4 \mathrm{~nm}$ (as determined by TEM) and the Ag mass concentration $20 \mathrm{mg} / \mathrm{L}$ (as determined by ICP-MS). These NPs will be referred to as "AgPEG40 NPs" in the text. A certified reference material (CRM) for tuna fish (ERM-CE464), obtained by Fluka Chemie GmbH (Buchs, Switzerland), was used for 

testing the accuracy of the ICP-MS analysis of acid digested tissues. The CRM did not contain any detectable amount of Ag.

To demonstrate the applicability of the method (sample preparation and spICP-MS) to "realistic" NPs, AgNPs with a broad size distribution instead of monomodal AgNPs size standards were selected. AgNPs thiolated with two different surface modifications: polyethylene glycol with a molecular weight of 550 g/mol $\left(\mathrm{PEG}_{550}\right)$ (AgPEG NPs) or sodium 11-mercaptoundecanoate $\left(\mathrm{SH}\left(\mathrm{CH}_{2}\right)_{10}-\mathrm{COONa}\right)(\mathrm{AgCOONa} \mathrm{NPs})$ were provided within the EU FP7 Nanosolutions project (www.nanosolutionsfp7.com/). Since these AgNPs were industrially produced (PlasmaChem GmbH, Berlin, Germany) the results are expected to provide a more real-life exposure scenario. A detailed description of the AgNP synthesis and characterization will be published elsewhere. Briefly, TEM analysis showed that the AgPEG NP suspension contained three populations: Ag spheres of 2-8 nm, Ag spheres close to 7-15 nm, and a third minor population of large and irregular particles in the 200-1000 nm size range. The AgCOONa NPs suspension comprised, besides the primary particles $(5-15 \mathrm{~nm})$, large assemblies of 100-500 nm containing multiple individual AgNP spheres of 5-15 nm. DLS analysis of AgNPs suspended in UPW confirmed the multimodal distribution for AgPEG NPs (average hydrodynamic diameter $\left(Z_{\text {ave }}\right): 30.7 \pm 0.2 \mathrm{~nm}$, polydispersity index (PDI): 0.457) and the bimodal distribution for AgCOONa NPs $\left(Z_{\text {ave }}: 121.0 \pm 0.8 \mathrm{~nm}, \mathrm{PDI}: 0.276\right)$. For AgPEG NPs in perfusion medium, a slightly broader size distribution was observed in comparison to UPW (Z $\mathrm{ave}_{\mathrm{ave}} 37.1 \pm 0.5 \mathrm{~nm}$, PDI: 0.555). For AgCOONa NPs in perfusion medium, the size distribution shifted to significantly larger sizes due to agglomeration/aggregation of the NPs $\left(Z_{\text {ave }}: 798.1 \pm 43.4 \mathrm{~nm}\right.$, PDI: 0.059). However, DLS as an intensity-based method is limited for such polydisperse mixtures of NPs, since the contribution to the total scattered light by the small particles is shielded by the larger ones. Mass fractions of dissolved Ag in the stock suspensions of AgPEG NPs and AgCOONa NPs were 4.9\% and 0.11\%, respectively.

\section{Instrumental}

For mixing of the homogenized placenta samples with enzyme solution and for homogenizing spiked samples, a MS2 minishaker (IKA Works, Inc., Wilmington, NC, USA) was used. After the addition of TMAH, tissue homogenate samples were placed into a Branson sonication bath (VWR International, Leicester, UK) at a frequency of $42 \mathrm{kHz}$ and an input power of $185 \mathrm{~W}$. pH values were measured with a PHM 240 pH/ION meter (Radiometer, Copenhagen, Denmark). For enzymatic digestion of the samples, a water bath with a HetoHMT 200 RS thermostat and a Telesystem HP15 magnetic stirrer (Holm \& Halby, Allerød, Denmark) were used. Tissue samples were digested with acid with the use of microwave system (turboWave 1500, MWS GmbH, Heerbrugg, Switzerland).

An 8800 Triple Quadrupole ICP-MS instrument (Agilent Technologies, California, USA) was used for single particle measurement of digested placenta tissue samples. Instrument tuning was performed prior to analysis by using a tuning solution according to the manufacturer's recommendation. Settings for the instrument are given in Table S1. 
A 7900 ICP-MS instrument (Agilent Technologies) was used for the measurements of Ag mass concentrations in acid digested tissue samples.

\section{Alkaline treatment}

A previously developed protocol for AuNPs in rat spleen ${ }^{22}$ was modified to be applicable for the treatment of a larger mass of wet tissue (previously $0.020 \mathrm{~g}$ ) by increasing the TMAH concentration from 5\% to $20 \%$. Briefly, a mass of $0.2 \mathrm{~g}$ of tissue homogenate (corresponding to $0.1 \mathrm{~g}$ of wet tissue) was weighted and mixed with $0.3 \mathrm{~mL}$ of UPW and $2 \mathrm{~mL}$ of TMAH $(25 \% \mathrm{v} / \mathrm{v})$ to achieve a final concentration of $20 \%$ TMAH. After placing the samples in the sonication bath for 1 hour at room temperature (RT), they were mixed on the rotator (Ferris wheel) at RT for 23 hours. Prior to spICP-MS measurements, the samples were diluted with UPW 20-times to achieve a TMAH concentration of $1 \%(\mathrm{v} / \mathrm{v})$. For further dilutions, a TMAH concentration of $1 \%(\mathrm{v} / \mathrm{v})$ was maintained. All samples were prepared in duplicates.

\section{Enzymatic treatment}

A protocol originally developed for AgNPs in lean chicken meat was applied. ${ }^{29}$ For the enzyme solution, 3 $\mathrm{g} / \mathrm{L}$ of Proteinase $\mathrm{K}$ and $0.5 \%$ SDS were diluted in enzyme buffer, consisting of $50 \mathrm{mM}$ ammonium bicarbonate buffer and $200 \mathrm{mg} / \mathrm{L}$ sodium azide at $\mathrm{pH} 7.4$. A mass of $0.2 \mathrm{~g}$ of tissue homogenate (corresponds to $0.1 \mathrm{~g}$ of wet tissue) was weighed into plastic tubes with round bottom (Karter Scientific Labware Manufacturing, Lake Charles, LA, USA). After the addition of $2.0 \mathrm{~mL}$ of the enzyme solution (60 $\mu \mathrm{g}$ of enzyme per mg of wet tissue) and $300 \mu \mathrm{L}$ of UPW, samples were shortly vortexed until no sample was sticking to the tubes walls. Sample were placed in the water bath at $37^{\circ} \mathrm{C}$ and magnetically stirred for 1 hour until no tissue fibres were visible. At the end of enzymatic treatment, the samples were placed in ice water to slow down the enzymatic digestion process. Prior to spICP-MS measurements, samples were appropriately diluted with UPW.

\section{Spiking experiments}

The efficiency of alkaline and enzymatic treatment for releasing the AgNPs from human placenta was validated with the use of the spiked placental tissue samples since no biological reference material with AgNPs was available. For both types of treatment, $100 \mathrm{mg}$ of tissue homogenates from control perfusion experiments were spiked with $10 \mu \mathrm{L}$ of diluted AgNP stock suspensions with Ag mass concentration of 329 $\mu \mathrm{g} / \mathrm{mL}$ for AgCOONa NPs and $134 \mu \mathrm{g} / \mathrm{mL}$ for AgPEG NPs. The achieved Ag mass concentrations in tissue were $26.8 \mathrm{mg} / \mathrm{kg}_{\text {tissue }}$ and $66.0 \mathrm{mg} / \mathrm{kg}_{\text {tissue }}$ for AgPEG and AgCOONa NPs, respectively. All samples were prepared in duplicates. A scheme of the study design is presented in Figure 1. The positive control (AgPEG40 NPs) was diluted $10^{6}$-times in UPW or the relevant matrices to a final mass concentration of 20 $\mathrm{ng} / \mathrm{L}$. This concentration resulted in a sufficient number of detected particles without exceeding the $10 \%$ contribution limit for multiple events as described above. 


\section{Particle analysis by spICP-MS}

Data processing was performed as described previously. ${ }^{32}$ Accurate sample flow rate $(0.1 \mathrm{rps})$ was daily determined by weighing of UPW at RT as a sample. Quantification of particle size (particle diameter) was based on a calibration curve constructed from a blank (UPW) and four concentration levels of certified standard solutions of ionic Ag ranging from 0.2 to $2.0 \mu \mathrm{g} / \mathrm{L}$. The isotope ${ }^{107} \mathrm{Ag}$ was detected using $3 \mathrm{~ms}$ dwell time for a total measurement time of $180 \mathrm{~s}$ (equivalent to 60000 data points). The ICP-MS signal intensity for each standard solution was acquired by averaging the signal intensity recorded during the $180 \mathrm{~s}$ measurement time. The transport efficiency was determined according to the "particle frequency" and "particle size" method. ${ }^{39}$

For determination of the transport efficiency based on the "particle frequency" method, a reference AuNP suspension with a known average particle diameter of $27.6 \mathrm{~nm}$ (based on measurements by transmission electron microscopy provided by NIST) and a gold mass concentration of $48.17 \pm 0.33 \mu \mathrm{g} / \mathrm{g}$ (information value provided by NIST), diluted $10^{7}$-times with UPW was analyzed. The transport efficiency was calculated as the percentage of all Au nanoparticles detected by spICP-MS versus the theoretical (calculated) particle number in the introduced sample volume.

The transport efficiency according to the "particle size" method was determined in the following way: First, a calibration curve that related ${ }^{197} \mathrm{Au}$ signal intensity (peak maximum of the intensity distribution) to particle mass was created using the reference AuNPs (particle mass $0.212 \mathrm{fg}$ ) in UPW. Second, a corresponding calibration curve was constructed by determining the average ${ }^{197} \mathrm{Au}$ signal intensity for ionic Au standards at $0,0.2,0.5$ and $1.0 \mu \mathrm{g} / \mathrm{L}$. The Au concentration was converted to Au mass by multiplication with sample flow rate and dwell time. The transport efficiency was determined by dividing the slope from the calibration curve made from the ionic Au standards by the slope from the calibration curve created from the AuNPs.

For each sample of AgNPs the ${ }^{107} \mathrm{Ag}$ signal intensity was recorded for 180-600 s using a dwell time of 3 ms (60000-200000 recorded data points). The recorded signal intensity data were plotted (in cps) versus number of "events", to create a signal distribution histogram using Microsoft Excel (Microsoft, WA, USA). The signal intensity threshold above which events were considered as NPs was set to a value that corresponded to a particle diameter of $25 \mathrm{~nm}$ for all samples. This value resulted from the presence of ionic $\mathrm{Ag}$ in some of the samples (tissues samples collected after $6 \mathrm{~h}$ of perfusion) which lead to an increase of the size limit of detection from $14 \mathrm{~nm}$ (determined in tissue samples collected at time $0 \mathrm{~h}$ with no ionic $\mathrm{Ag}$ present) to $25 \mathrm{~nm}$. The application of the same threshold for all samples ensured that a direct comparison of particle mass and number concentrations as well as median particle diameters between samples was possible. The same size threshold (i.e. $25 \mathrm{~nm}$ ) was applied also for distinguishing particle events from the 
instrumental background and ionic Ag signal for the AgPEG40 control particles. The dilution factors of the samples were adjusted in such a way that at least 400 particles were detected during one acquisition, to reduce the relative standard deviation of the Poisson distribution to $5 \%$. At the same time, the number of readings/data points with particle events was limited to $20 \%$ to keep the contribution of multiple particle events to the size distribution below $10 \%$ according to Poisson statistics. All samples were prepared in duplicates.

To prevent AgNPs from sticking to the ICP-MS sample introduction system and to avoid a memory effect during ICP-MS measurements, the following washing procedure was applied after each sample: Rinsing with a mixture of $1 \%(\mathrm{v} / \mathrm{v}) \mathrm{HCl}, 1 \%(\mathrm{v} / \mathrm{v}) \mathrm{HNO}_{3}$ and $0.1 \%(\mathrm{~m} / \mathrm{v})$ Triton $\mathrm{X}-100$ for $1 \mathrm{~min}$ at $0.5 \mathrm{rpm}$ $(1.7 \mathrm{~mL} / \mathrm{min})$, followed by rinsing with UPW for $30 \mathrm{~s}$ at $0.3 \mathrm{rpm}(1 \mathrm{~mL} / \mathrm{min})$. With the applied washing procedure, a minor degree of carryover (typically between 1 and 40 NPs during 3 min of analysis) was observed. As the number of NPs in the analyzed samples was in the range of 1000 NPs (per 3 min analysis), this was evaluated as acceptable.

\section{Results and discussion}

\section{Investigation of potential matrix effects on calibration}

First, we wanted to evaluate whether ionic Ag standards (for the determination of the ICP-MS response) and AuNPs (for determination of the transport efficiency) should be prepared in the same matrix as the digested tissue samples or whether they can be prepared in UPW. Therefore, the transport efficiency based on the particle frequency and particle size method was determined by diluting AuNP and ionic Au standards in the relevant matrices (Table 1). A solution of 1\% TMAH represented the matrix for alkaline treatment, while a 30-times diluted enzyme solution was used as a matrix for enzymatic treatment (as enzymatic digests were diluted 30-times with UPW after enzymatic treatment). The ICP-MS response for ionic Au and Ag was determined by measuring a blank (UPW or relevant matrix) and different concentrations of ionic $\mathrm{Au}(0.2$, 0.5 and $1.0 \mu \mathrm{g} / \mathrm{L})$ or Ag standards $(0.2,0.5,1.0$ and $2.0 \mu \mathrm{g} / \mathrm{L})$, respectively.

\section{Insert Table 1 about here}

Similar transport efficiencies (6-8\%) were determined with the two methods, particle frequency and particle size method, independently of the used matrix (Table 1). The only exception was observed for the transport efficiency (11\%) determined by the particle size method in the $1 \%$ TMAH matrix. This was related to the 54\% higher ICP-MS response for ionic Au in 1\% TMAH in comparison to UPW and enzyme solution. Possibly, TMAH has a stabilizing effect for the $\mathrm{Au}$ ions and reduced the loss of $\mathrm{Au}$ ions in the sample introduction system. However, TMAH most probably does not have this effect for AuNPs and consequently, the transport efficiency (as it is based on the transport efficiency for ions) was overestimated. The ICP-MS response for ionic Ag solution in 1\% TMAH and enzyme solution decreased by $19 \%$ and $56 \%$, respectively, 
in comparison to the ICP-MS response for ionic Ag solution in UPW, which is typically used as diluent for ionic standards in ICP-MS ${ }^{40}$ (Table 1). The suppression of the $\mathrm{Ag}+$ sensitivity by the matrix due to the reactions with solution components relevant to environmental and biological systems was also observed in a study by Liu et al. ${ }^{41}$ In general, a reduced ICP-MS response in a certain matrix could be explained by: 1 ) increased adhesion of ions to surfaces of the sample container and the sample introduction system (especially the tubings), 2) reduced nebulization efficiency (due to increased droplet size) and 3) plasma effects that lead to a reduced degree of ionization (caused by decreased plasma temperature). Explanation 1) would mean that matrix-matching should not be applied if the matrix influences the ion adhesion but not the NP adhesion. Explanation 3) would mean that matrix-matching should be applied as the plasma effect would equally affect ions and NPs. Reduced nebulization efficiency (Explanation 2) could already be excluded based on the finding of similar transport efficiencies (Table 1). To test which explanation is more likely, matrix matching was not applied (i.e. ICP-MS response determined for ionic Ag in UPW independent of matrix) for sizing and quantification of AgPEG40 NPs suspended in UPW, 1\% TMAH and enzyme solution (30-times dilution) (Table 2). As can be seen (Table 2, Fig. 2), particle mass concentrations and median particle sizes obtained for AgPEG40 NPs suspended in UPW and AgPEG40 NPs spiked to 1\% TMAH or enzyme solution were not significantly different (t-test). This proved that using UPW as matrix for the ionic standards was correct, as the use of the lower response determined for Ag ions in enzyme solution or TMAH solution for the calculations would have resulted in too low mass concentrations ( $56 \%$ or 19 lower) and too high median diameters (25\% higher for enzyme matrix, i.e. around $43 \mathrm{~nm})$ of the AgPEG40 NPs. This makes it likely that explanation 1 (adhesion to sample introduction system) is the reason for the decreased response, as this effects the response of the ions (standards) but not the NPs.

\section{Insert Figure 2 about here}

Insert Table 2 about here

\section{Comparison of spike recoveries and AgNP size distributions after enzymatic and alkaline treatment of placenta tissues}

In order to investigate how the alkaline and enzymatic treatment influences the mass concentrations and size distribution of AgNPs in placental tissue, $100 \mathrm{mg}$ of tissue homogenates from a control perfusion experiment (placenta samples were collected before the start of the perfusion experiment) were spiked with AgNPs stock suspensions to achieve final Ag mass concentrations of $26.8 \mathrm{mg} / \mathrm{kg}_{\text {tissue }}$ for AgPEG NPs and $66.0 \mathrm{mg} / \mathrm{kg}_{\text {tissue }}$ for AgCOONa NPs. These concentrations were selected to be approximately the same as the AgNPs concentrations used in the perfusion experiments. After spiking, samples were homogenized by the use of a vortex mixer for 1 minute to assure a proper mixing of tissue homogenate and AgNPs before the enzymatic or alkaline treatment. Suspensions of AgNPs at the same Ag concentrations were prepared in UPW as well. Prior to spICP-MS analysis, spiked samples and suspensions of AgNPs in UPW were diluted 
in the same way in order to make comparison between the determined mass concentrations and sizes possible.

The particle size distributions of the two types of AgNPs, AgPEG and AgCOONa, in enzymatically treated tissue and UPW were similar (Fig. 3 and Fig. 4, left graphs) showing that enzymatic digestion did not significantly affect the particle sizes, e.g. through aggregation or dissolution. The determined median particle diameters were around $27 \mathrm{~nm}$ for AgPEG and $34 \mathrm{~nm}$ for $\mathrm{Ag} \mathrm{COOH}$, and not statistically different before and after enzymatic treatment for both particle types (Table 3). Median diameters of AgNPs determined by spICP-MS were larger compared to the primary particle sizes observed by TEM due to relatively high size detection limit of spICP-MS $(25 \mathrm{~nm})$. Therefore, a relatively large fraction of the studied AgNPs that were smaller than $25 \mathrm{~nm}$ could not be detected by spICP-MS. Higher (total) Ag mass recoveries were obtained in enzymatically treated tissue (98 and 124\%) in comparison to UPW (44 and 78\%) for AgPEG and AgCOONa, respectively, which indicated a stabilizing effect of the enzymatic digest. The fraction of AgNPs $>25 \mathrm{~nm}$ relative to the total Ag mass concentration was not affected by the enzymatic treatment and remained $1 \%$ for $\mathrm{AgPEG}$ and $40 \%$ for $\mathrm{AgCOONa}$ as in the case of dilution in UPW. The finding of high recoveries after enzymatic treatment is in contrast to the results of one of our previous studies of gold NPs in rat spleen. ${ }^{22}$ There, much lower particle mass recoveries (about 25\%) were determined by spICPMS following enzymatic digestion. This can be attributed to the different enzymatic digestion protocol used in this study, where an approximately 10-times lower Proteinase K concentration was used (around $4 \mu \mathrm{g}$ of Proteinase K per mg wet tissue). The present study makes use of an optimized protocol (60 $\mu \mathrm{g}$ of Proteinase $\mathrm{K}$ per mg of wet tissue) ${ }^{29}$ which results in more efficient degradation of the matrix and/or better stabilization of the NPs.

After alkaline treatment, the particle size distributions of the two types of AgNPs, AgPEG and AgCOONa, showed the occurrence of larger NPs in comparison to UPW (Fig. 3 and Fig. 4, right graphs). The determined median particle diameters increased from around $27 \mathrm{~nm}$ to $36 \mathrm{~nm}$ for AgPEG and from 34 $\mathrm{nm}$ to $45 \mathrm{~nm}$ for Ag COOH (Table 3). Higher (total) Ag mass recoveries were obtained in alkaline treated tissue (118\% for AgPEG and 133\% for AgCOONa) in comparison to UPW (44\% for AgPEG and 78\% for $\mathrm{AgCOONa})$. The fraction of AgNPs $>25 \mathrm{~nm}$ relative to the total Ag mass concentration increased from 1\% in UPW to 93\% after alkaline treatment for AgPEG and from 40\% to 115\% for AgCOONa. These findings indicated agglomeration/aggregation of both types of AgNPs due to the alkaline treatment of the tissue. A further possible mechanism could be the formation of large AgNPs from ionic Ag that could be already present in the stock AgNP suspensions and/or could originate from AgNPs dissolution during the alkaline treatment.

Insert Figure 3 and Figure 4 about here 
In the only published study, that used TMAH solubilization followed by spICP-MS analysis for releasing of AgNPs from biological matrices so far, no significant ( $>5 \mathrm{~nm}$ ) change of the size distribution of $100 \mathrm{~nm}$ AgNPs with PVP coating was observed after alkaline treatment of ground beef (Ag spiking concentration of $0.019 \mathrm{mg} / \mathrm{kg}$ wet weight). ${ }^{21}$ A "nearly identical" size distribution was described for a mixture of $60 \mathrm{~nm}$ and $100 \mathrm{~nm}$ AgNPs. The presented histograms indicated a slight shift of the size distribution to larger size values after alkaline treatment.

\section{Insert Table 3 about here}

In order to investigate if alkaline or enzymatic treatments caused particle formation from ionic $\mathrm{Ag}, 10$ $\mu \mathrm{L}$ of $10 \mu \mathrm{g} / \mathrm{mL}$ ionic $\mathrm{Ag}$ was spiked to $100 \mathrm{mg}$ of control tissue homogenates (50 $\mathrm{mg}$ of tissue), which results in $2 \mathrm{mg}$ of $\mathrm{Ag}^{+} / \mathrm{kg}_{\text {tissue}}$, and subjected to the alkaline and enzymatic treatment. This concentration was selected to be approximately the same as the expected Ag tissue concentration if all Ag, which was dosed to the perfusion experiment $(1 \mathrm{mg} / \mathrm{L})$, accumulates in the analysed tissue $\left(4 \mathrm{mg} \mathrm{of} \mathrm{Ag}^{+} / \mathrm{kg}_{\text {tissue }}\right) .1 \mathrm{mg} / \mathrm{L}$ of ionic $\mathrm{Ag}$ was also prepared in the matrices relevant to each treatment type, i.e. 1\% TMAH or enzyme solution (30-times diluted) and measured by spICP-MS, applying the same dilution factor before analysis (20,000times). The number of detected particles, Ag mass concentration ( $>25 \mathrm{~nm}$ and $\leq 25 \mathrm{~nm}$ ) and median particle size observed in 3 min long run are presented in Table 4. As it can be seen, a significant number of particles $(8,383)$ was formed after alkaline treatment of the spiked placental tissue sample with a median particle size of $33 \mathrm{~nm}$, while 50 particles with $29 \mathrm{~nm}$ median size were detected for the same concentration of ionic Ag in 1\% TMAH. Ag precipitation during alkaline treatment apparently occurs due to the components present in the tissue or perfusion medium (e.g. chlorides, sulfides) and not only because of the use of 1\% TMAH. Gomes et al. ${ }^{42}$ observed $\mathrm{Ag}$ particle formation in alkaline conditions in the presence of alkoxides as reducing agents, formed from any molecule containing a hydroxyl $(\mathrm{OH})$ group. In our case, alkaline TMAH and the presence of the tissue that contains proteins with $-\mathrm{OH}$ groups might create an ideal environment for the formation of particles. Enzymatic treatment on the other hand did not cause significant formation of particles, neither in treated placental tissue nor in enzymatic solution alone. $2 \pm 1$ and $35 \pm 5$ particles were detected in enzymatically and alkaline treated control tissue samples, respectively, probably due to the carryover from previous measurements.

\section{Insert Table 4 about here}

From the data presented in Table 4 it can be concluded that Ag precipitation contributed, at least to a certain extent, to the above described results for AgPEG and AgCOONa in alkaline treated tissue. It was also demonstrated that TMAH itself does not lead to a significant particle formation when there is no tissue present. In the study by Gray et al., ${ }^{21}$ no particle formation from ionic Ag was observed. The spiking 
concentration for ionic Ag were 50-times lower (0.04 $\mathrm{mg} \mathrm{Ag}^{+} / \mathrm{kg}_{\text {tissue }}$ ) compared to the concentration used in

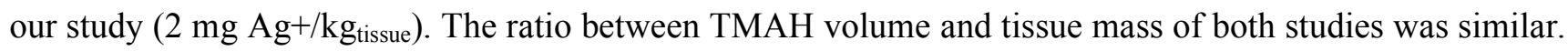
The method described by Gray et al. ${ }^{21}$ adds $10 \mathrm{~mL}$ of TMAH to $0.5 \mathrm{~g}$ tissue, resulting in a final TMAH concentration of $20 \%$. We use $0.1 \mathrm{~g}$ tissue (in $0.2 \mathrm{~g}$ tissue homogenate) and add $2 \mathrm{~mL}$ of TMAH and $0.3 \mathrm{~mL}$ UPW, resulting in a final TMAH concentration of $20 \%$ as well. Further work is required to understand the observed differences of the two studies.

\section{Quantification and characterization of AgNPs accumulated in human placenta in the ex vivo human placental perfusion model}

Enzymatic treatment of the placental tissue followed by spICP-MS analysis was proven to be effective for characterization and quantification of AgCOONa and AgPEG NPs, which were spiked to placental tissue samples. However, accumulation of NPs under real exposure scenarios involves many dynamic interactions between NPs, matrix and biological processes of the target organism. ${ }^{25}$ Therefore, for testing if the same procedure was capable of extracting AgNPs accumulated under a realistic exposure scenario, placental tissues from human ex vivo placenta perfusion experiments were investigated.

The median sizes and mass fractions of AgNPs > $25 \mathrm{~nm}$ for AgPEG NPs and AgCOONa NPs accumulated in the placental tissue after $6 \mathrm{~h}$ of perfusion (data not shown) as well as size distributions (Fig. S1, ESI) were determined by spICP-MS and were comparable to the values obtained for the suspensions in UPW and in the spiking experiments (Table 3). This indicates that either no dissolution of the AgNPs occurred during their accumulation in human placental tissue or that spICP-MS cannot provide information about the agglomeration state of the NPs in the tissue as it can be altered by the high sample dilution. ${ }^{43}$

Furthermore, Ag mass concentrations of AgNPs accumulated in placental tissue obtained by spICP-MS after enzymatic treatment were compared with the concentrations obtained by conventional ICP-MS after digestion of the tissues with acids (Table 5).

\section{Insert Table 5 about here}

There was no significant difference (t-test, $\mathrm{p}>0.01$ ) between the Ag concentrations determined after enzymatic treatment (spICPMS) and acid digestion (conventional ICPMS) in the tissue samples, suggesting that enzymatic treatment of the placental tissue is capable of extracting all AgNPs from tissues, similar to a more traditional acid digestion.

\section{Conclusions}

The results showed that enzymatic treatment with Protease $\mathrm{K}$ is a suitable method for characterization of different types of AgNPs in placental tissue. Alkaline treatment followed by sp-ICP-MS analysis could not 
be used for extracting AgNPs from the placental tissue samples because it changes the state of AgNPs, most probably by $\mathrm{Ag}^{+}$precipitation and/or AgNP aggregation. Our work further showed that matrix matching of ionic Ag standards cannot be applied in the case of enzymatic digestion and alkaline solubilization probably due to increased adhesion of ions in the sample introduction system in these matrices. In tissue spiking experiments, the same size distribution as for the pristine AgNPs were determined although no matrix matching was performed. The results show that matrix matching can lead to inaccurate results and that UPW can be a suitable diluent.

The optimized analytical method with the use of enzymatic digestion coupled to spICP-MS was successfully applied for quantification and sizing of AgPEG and AgCOONa NPs accumulated in placenta during ex vivo human perfusion experiment. Ag mass recovered from placental tissue using enzymatic digestion coupled to spICPMS analysis was comparable to the total Ag mass recovered using microwaveassisted digestion. Besides quantifying AgNPs accumulated in placenta, the method also provides additional information on characterization of AgNPs (e.g. size distribution, ionic/particulate form of Ag) that can significantly contribute to the interpretation of toxicological data generated during human placenta perfusion experiments.

Despite many advantages of spICP-MS, the technique still has several limitations. It is limited in terms of relatively high size detection limits. A relatively large fraction of the studied AgNPs could not be detected by spICP-MS as the NPs were in the size range of 2-15 $\mathrm{nm}$. Moreover, the required high sample dilution of the NPs suspensions and sample preparation in the case of (semi)solid matrices most likely affects agglomeration/aggregation and/or dissolution state of the NPs. ${ }^{43}$ Also, for accurate determination of NP size by spICP-MS, the shape, density and chemical composition of the analyzed NPs need to be known. In addition, standard reference materials of NPs with very carefully determined properties are needed to standardize spICP-MS technique, which includes the assessment of the reliability and variability of size and concentration determinations.

\section{Conflict of interests}

There are no conflicts to declare.

\section{Acknowledgements}

We thank Agilent for providing the Agilent 8800 instrument. The research leading to these results has received funding from the European Union's Seventh Framework Programme (FP7/2007-2013) under grant agreement $n^{\circ} 309329$ (NANOSOLUTIONS). This work was further supported by the Ad futura scholarship (Slovene Human Resources and Scholarship Fund) that financed the research visit of Janja Vidmar at the Technical University of Denmark.

\section{References}


M. Ahamed, M. S. AlSalhi and M. K. J. Siddiqui, Clin. Chim. Acta, 2010, 411, 1841-1848.

T. Buerki-Thurnherr, U. Von Mandach and P. Wick, Swiss Med. Wkly., 2012, 142, 1-9.

Y. Lee, J. Choi, P. Kim, K. Choi, S. Kim, W. Shon and K. Park, 2012, 28, 139-141.

4 E. a. Melnik, Y. P. Buzulukov, V. F. Demin, V. a. Demin, I. V. Gmoshinski, N. V. Tyshko and V. a. Tutelyan, Acta Naturae, 2013, 5, 107-115.

5 J. Wu, C. Yu, Y. Tan, Z. Hou, M. Li, F. Shao and X. Lu, Environ. Res., 2015, 138, 67-73.

6 M. Charehsaz, K. S. Hougaard, H. Sipahi, a I. D. Ekici, C. Kaspar, M. Culha, U. U. Bucurgat and a Aydin, Daru-Journal Pharm. Sci., 2016, 24, 1-13.

7 L. Campagnolo, M. Massimiani, L. Vecchione, D. Piccirilli, N. Toschi, A. Magrini, E. Bonanno, M. Scimeca, L. Castagnozzi, G. Buonanno, L. Stabile, F. Cubadda, F. Aureli, P. H. Fokkens, W. G. Kreyling, F. R. Cassee and A. Pietroiusti, Nanotoxicology, 2017, 0, 1-36.

8 E. Paul, M.-L. Franco-Montoya, E. Paineau, B. Angeletti, S. Vibhushan, A. Ridoux, A. Tiendrebeogo, M. Salome, B. Hesse, D. Vantelon, J. Rose, F. Canouï-Poitrine, J. Boczkowski, S. Lanone, C.

Delacourt and J.-C. Pairon, Nanotoxicology, 2017, 11, 484-495.

9 Enders and Blankenship, Adv. Drug Deliv. Rev., 1999, 38, 3-15.

10 M. Panigel, M. Pascaud and J. L. Brun, J. Physiol. (Paris)., 1967, 59, 277.

11 C. Muoth, L. Aengenheister, M. Kucki, P. Wick and T. Buerki-Thurnherr, Nanomedicine, 2016, 11, 941-957.

12 S. Grafmüller, P. Manser, H. F. Krug, P. Wick and U. von Mandach, J. Vis. Exp., 2013, 1-7.

13 E. Bolea, J. Jiménez-Lamana, F. Laborda, I. Abad-Álvaro, C. Bladé, L. Arola and J. R. Castillo, Analyst, 2014, 139, 914-922.

14 S. Kittler, C. Greulich, J. Diendorf, M. Köller and M. Epple, Chem. Mater., 2010, 22, 4548-4554.

15 E. Navarro, B. Wagner, F. Marconi, R. Kaegi, N. Odzak, P. O. Box, E. Navarro, F. Piccapietra, B. Wagner, F. Marconi, R. Kaegi, N. Odzak, L. Sigg and R. Behra, Environ. Sci. Technol., 2008, 42, 8959-8964.

16 Z. Xiu, Q. Zhang, H. L. Puppala, V. L. Colvin and P. J. J. Alvarez, Nano Lett., 2012, 12, 4271-4275.

17 F. Laborda, E. Bolea, G. Cepriá, M. T. Gómez, M. S. Jiménez, J. Pérez-Arantegui and J. R. Castillo, Anal. Chim. Acta, 2016, 904, 10-32.

18 I.-L. Hsiao, F. S. Bierkandt, P. Reichardt, A. Luch, Y.-J. Huang, N. Jakubowski, J. Tentschert and A. Haase, J. Nanobiotechnology, 2016, 14, 1-13.

19 J. Jiménez-Lamana, F. Laborda, E. Bolea, I. Abad-Álvaro, J. R. Castillo, J. Bianga, M. He, K. Bierla, S. Mounicou, L. Ouerdane, S. Gaillet, J.-M. Rouanet and J. Szpunar, Metallomics, 2014, 6, $2242-$ 2249.

20 C. Degueldre and P.-Y. Favarger, Colloids Surfaces A Physicochem. Eng. Asp., 2003, 217, 137-142.

21 E. P. Gray, J. G. Coleman, A. J. Bednar, A. J. Kennedy, J. F. Ranville and C. P. Higgins, Environ. Sci. Technol., 2013, 47, 14315-14323. 
22 K. Loeschner, M. S. J. Brabrand, J. J. Sloth and E. H. Larsen, Anal. Bioanal. Chem., 2014, 406, $3845-3851$.

23 H. Klingberg, L. B. Oddershede, K. Loeschner, E. H. E. H. Larsen, S. Loft and P. Møller, Toxicol. Res. (Camb)., 2015, 4, 655-666.

24 M. Van Der Zande, R. J. Vandebriel, E. Van Doren, E. Kramer, Z. H. Rivera, C. S. Serrano-Rojero, E. R. Gremmer, J. Mast, R. J. B. Peters, P. C. H. Hollman, P. J. M. Hendriksen, H. J. P. Marvin, A. A. C. M. Peijnenburg and H. Bouwmeester, ACS Nano, 2012, 6, 7427-7442.

25 S. Makama, R. Peters, A. Undas and N. W. Van Den Brink, Environ. Chem., 2015, 12, 643-651.

26 R. J. B. Peters, Z. H. Rivera, G. Van Bemmel, H. J. P. Marvin, S. Weigel and H. Bouwmeester, Anal. Bioanal. Chem., 2014, 406, 3875-3885.

27 R. Peters, Z. Herrera-Rivera, A. Undas, M. van der Lee, H. Marvin, H. Bouwmeester and S. Weigel, J. Anal. At. Spectrom., 2015, 30, 1274-1285.

28 K. Loeschner, J. Navratilova, R. Grombe, T. P. J. Linsinger, C. Købler, K. Mølhave and E. H. Larsen, Food Chem., 2015, 181, 78-84.

29 K. Loeschner, J. Navratilova, C. Købler, K. Mølhave, S. Wagner, F. Von Der Kammer and E. H. Larsen, Anal. Bioanal. Chem., 2013, 405, 8185-8195.

30 B. Kollander, F. Widemo, E. Ågren, E. H. Larsen and K. Loeschner, Anal. Bioanal. Chem., 2017, 409, 1877-1885.

31 F. Gallocchio, G. Biancotto, V. Cibin, C. Losasso, S. Belluco, R. Peters, C. Cascio, S. Weigel, P. Tromp, F. Gobbo, S. Catania and A. Ricci, .

32 K. Loeschner, C. F. Harrington, J.-L. Kearney, D. J. Langton and E. H. Larsen, Anal. Bioanal. Chem., $2015,407,4541-4554$.

33 Y. Dan, W. Zhang, R. Xue, X. Ma, C. Stephan and H. Shi, Environ. Sci. Technol., 2015, 49, 30073014.

34 J. Jiménez-Lamana, J. Wojcieszek, M. Jakubiak, M. Asztemborska and J. Szpunar, J. Anal. At. Spectrom., 2016, 31, 2321-2329.

35 Y. Dan, X. Ma, W. Zhang, K. Liu, C. Stephan and H. Shi, Anal. Bioanal. Chem., 2016, 408, 51575167.

36 D. Bao, Z. G. Oh and Z. Chen, Front. Plant Sci., 2016, 7, 32.

37 S. Grafmueller, P. Manser, L. Diener, P. A. Diener, X. Maeder-Althaus, L. Maurizi, W. Jochum, H. F. Krug, T. Buerki-Thurnherr, U. von Mandach and P. Wick, Environ. Health Perspect., 2015, 123, $1280-1286$.

38 P. Wick, A. Malek, P. Manser, D. Meili, X. Maeder-Althaus, L. Diener, P. A. Diener, A. Zisch, H. F. Krug and U. Von Mandach, Environ. Health Perspect., 2010, 118, 432-436.

39 H. E. Pace, N. J. Rogers, C. Jarolimek, V. A. Coleman, C. P. Higgins and J. F. Ranville, Anal. Chem., 2011, 83, 9361-9369. 

nanoparticles in aqueous media via single particle inductively coupled plasma mass spectrometry, .

41 J. Liu, K. E. Murphy, M. R. Winchester and V. A. Hackley, Anal. Bioanal. Chem., 2017, 409, 60276039.

42 J. F. Gomes, A. C. Garcia, E. B. Ferreira, C. Pires, V. L. Oliveira, G. Tremiliosi-Filho and L. H. S. Gasparotto, Phys Chem Chem Phys, 2015, 17, 21683-21693.

43 A. Hineman and C. Stephan, J. Anal. At. Spectrom., 2014, 29, 1252.

\section{Caption to figures:}

Fig.1 Schematic presentation of the quantification and characterization of AgNPs in spiking experiments and AgNPs accumulated in human placenta in the ex vivo human placental perfusion model.

Fig. 2 Particle size distribution (bin size $2 \mathrm{~nm}$ ) obtained by spICPMS for AgPEG40 NPs suspended in UPW and AgPEG40 NPs spiked to $1 \%$ TMAH or enzyme solution. 
Fig. 3 Particle size distribution (bin size $2 \mathrm{~nm}$ ) obtained by spICPMS for AgPEG NPs in placental tissue after enzymatic (left; gray histogram) or alkaline treatment (right; white histogram). The particle size distribution for AgPEG NPs in UPW is presented for comparison (black histograms).

Fig. 4 Particle size distribution (bin size $2 \mathrm{~nm}$ ) obtained by spICPMS for AgCOONa NPs in placental tissue after enzymatic (left; gray histogram) or alkaline treatment (right; white histogram). The particle size distribution for AgPEG NPs in UPW is presented for comparison (black histograms). 
Table 1 Comparison of the transport efficiencies (calculated with particle frequency and particle size method by diluting AuNPs and ionic Au standards in relevant matrices, respectively) and ICP-MS responses for ionic Ag and ionic Au standards with related $\mathrm{R}^{2}$ values prepared in relevant matrices. ICP-MS responses for ionic Ag and ionic Au standards in 1\% TMAH and enzyme solution are expressed as percentages in relation to the responses determined in UPW. Results present mean and standard deviation of the samples measured on two different days

\begin{tabular}{|c|c|c|c|c|c|c|c|}
\hline & \multicolumn{2}{|c|}{ Transport efficiency (\%) } & \multirow{2}{*}{$\begin{array}{l}\text { Ionic Au } \\
\text { ICP-MS } \\
(\%)\end{array}$} & \multicolumn{4}{|c|}{ Ionic Ag } \\
\hline Matrix & $\begin{array}{l}\text { Particle frequency } \\
\text { method }\end{array}$ & $\begin{array}{l}\text { Particle size } \\
\text { method }\end{array}$ & & response & $\mathrm{R}^{2}$ & $\begin{array}{l}\text { ICP-MS response } \\
(\%)\end{array}$ & $\mathrm{R}^{2}$ \\
\hline UPW & 5.8 & 6.7 & 100 & & 0.9971 & 100 & 0.9978 \\
\hline $1 \%$ TMAH & 7.1 & 11.2 & $154 \pm 2$ & & 0.9999 & $81 \pm 24$ & 0.9958 \\
\hline Enzyme solution & 7.8 & 8.0 & $87 \pm 24$ & & 0.9996 & $44 \pm 1$ & 0.9785 \\
\hline
\end{tabular}


Table $2 \mathrm{Ag}$ mass concentration of NPs and background and median size for AgPEG40 NPs prepared in UPW and matrices relevant to each treatment type at a mass concentration of $20 \mathrm{ng} / \mathrm{L}(\mathrm{N}=2)$. Transport efficiency (with the use of the "particle size method") and ICP-MS response were determined in UPW

\begin{tabular}{llllll}
\hline $\begin{array}{l}\text { Matrix in which } \\
\text { NPs } \\
\text { suspended }\end{array}$ & $\begin{array}{l}\text { Mass conc. } \\
\text { AgNPs (ng/L) }\end{array}$ & $\begin{array}{l}\text { Ag mass conc. } \\
\text { of background } \\
(\mathrm{ng} / \mathrm{L})\end{array}$ & $\begin{array}{l}\mathrm{Ag} \text { mass } \\
\text { recovery* } \\
(\%)\end{array}$ & $\begin{array}{l}\text { Median particle } \\
\text { size } \\
(\mathrm{nm})\end{array}$ \\
\hline $\mathrm{UPW}$ & $10.5 \pm 0.3$ & $1.9 \pm 0.8$ & $65 \pm 1$ & $34.2 \pm 0.0$ \\
$1 \% \mathrm{TMAH}$ & $12.3 \pm 0.4$ & $<\mathrm{LOD}^{1}$ & $62 \pm 2$ & $33.5 \pm 0.2$ \\
Enzyme solution & $13.7 \pm 0.3$ & $\mathrm{LOD}^{2}$ & $68 \pm 1$ & $34.5 \pm 0.0$ \\
\hline
\end{tabular}

*Calculated from the total Ag mass concentration (NPs + background) determined by spICP-MS in comparison to the Ag mass concentration provided by the manufacturer $\left(20 \mathrm{mg} / \mathrm{L}\right.$; diluted $10^{6}$-times to $\left.20 \mathrm{ng} / \mathrm{L}\right)$ ${ }^{1} \mathrm{LOD}_{\text {backgorund }}$ in $1 \% \mathrm{TMAH}=11 \mathrm{ng} / \mathrm{L}$

${ }^{2} \mathrm{LOD}_{\text {backgorund }}$ in enzyme solution $=42 \mathrm{ng} / \mathrm{L}$ 
Table 3 Ag mass recovery, mass fraction of AgNPs $>25 \mathrm{~nm}$ and median particle size for AgPEG and AgCOONa in UPW (N=4) and in placental tissue after enzymatic and alkaline treatment $(\mathrm{N}=2)$ (mean \pm standard deviation)

\begin{tabular}{lllll} 
AgNP type & Treatment & $\begin{array}{l}\text { Ag mass recovery* } \\
(\%)\end{array}$ & $\begin{array}{l}\text { Mass fraction of } \\
\text { AgNPs }>25 \mathrm{~nm}^{* *} \\
(\%)\end{array}$ & $\begin{array}{l}\text { Median } \\
\text { size }(\mathrm{nm})\end{array}$ \\
\hline \multirow{3}{*}{ AgPEG } & UPW & $44 \pm 7$ & $1.0 \pm 0.5$ & $27.3 \pm 0.1$ \\
& Enzymatic treatment & $98 \pm 6$ & $1.5 \pm 0.7$ & $27.5 \pm 0.1$ \\
& Alkaline treatment & $118 \pm 2$ & $93 \pm 1$ & $35.5 \pm 0.5$ \\
\hline \multirow{3}{*}{ AgCOONa } & UPW & $78 \pm 8$ & $40 \pm 4$ & $34.1 \pm 0.4$ \\
& Enzymatic treatment & $124 \pm 1$ & $37.0 \pm 5$ & $34.2 \pm 0.3$ \\
& Alkaline treatment & $133 \pm 13$ & $115 \pm 17$ & $45.2 \pm 2.3$ \\
\hline
\end{tabular}

*Calculated from the total Ag mass concentration (NPs + background) determined by spICP-MS in comparison to the Ag mass concentration expected in the spiked tissue samples (calculated based on the Ag mass concentration of the spiking suspension, spiking volume and dilution factors)

**relative to the total Ag mass concentration $(>25 \mathrm{~nm}$ and $\leq 25 \mathrm{~nm}$ ) determined by spICP-MS 
Table $4 \mathrm{Ag}$ mass concentration, median particle size and number of particles, detected by spICP-MS analysis, for the enzymatically or alkaline treated control tissue samples, $1 \% \mathrm{TMAH}$ and enzymatic solution, spiked with $1 \mathrm{mg} / \mathrm{L}$ of ionic $\mathrm{Ag}$ (20,000-times diluted before analysis to $50 \mathrm{ng} / \mathrm{L}$ ). Results represent the average value with the standard deviation between two replicates.

\begin{tabular}{|c|c|c|c|c|c|}
\hline $\begin{array}{l}\text { Treatment } \\
\text { type }\end{array}$ & Matrix & $\begin{array}{l}\text { Ag mass conc. } \\
(>\quad 25 \mathrm{~nm}) \\
(\mathrm{ng} / \mathrm{L})\end{array}$ & $\begin{array}{l}\text { Ag mass conc. } \\
(\leq \quad 25 \quad \mathrm{~nm}) \\
(\mathrm{ng} / \mathrm{L})\end{array}$ & $\begin{array}{l}\text { Number } \\
\text { particles }\end{array}$ & $\begin{array}{l}\text { Median } \\
\text { particle } \\
(\mathrm{nm})\end{array}$ \\
\hline \multirow{2}{*}{ Alkaline } & spiked control tissue & $32.8 \pm 4.2$ & $17.7 \pm 4.8$ & $8,383 \pm 907$ & $33 \pm 2$ \\
\hline & TMAH & $0.235 \pm 0.128$ & $24.7 \pm 1.5$ & $50 \pm 13$ & $29 \pm 1$ \\
\hline \multirow{2}{*}{ Enzymatic } & spiked control tissue & $0.320 \pm 0.002$ & $46.7 \pm 5.4$ & $88 \pm 52$ & $26 \pm 0$ \\
\hline & enzymatic solution & $0.055 \pm 0.000$ & $31.3 \pm 0.6$ & $38 \pm 4$ & $25 \pm 0$ \\
\hline
\end{tabular}


Table 5 Comparison of Ag concentrations (in nanograms of Ag per gram of placental tissue) in placental tissues collected after 6 $\mathrm{h}$ of perfusion, obtained by spICP-MS after enzymatic treatment and by conventional ICP-MS after digestion with acids. The given values represent the mean \pm STD of two determinations for each sample. Presented are also $p$-values (t-test, $p<0.01)$ for comparison of Ag concentrations between two treatments.

\begin{tabular}{llll} 
& $\begin{array}{l}\text { Enzymatic digestion } \\
\text { (spICP-MS) }\end{array}$ & $\begin{array}{l}\text { Acid digestion } \\
\text { (ICP-MS) }\end{array}$ & \\
Perfusion experiment & ng/g & ng/g & p-value \\
\hline AgPEG NPs & $3,994 \pm 407$ & $2,821 \pm 262$ & 0.305 \\
AgCOONa NPs & $12,597 \pm 848$ & $13,720 \pm 6544$ & 0.827 \\
Ag + & $765 \pm 110$ & $879 \pm 12$ & 0.351 \\
control & $<20.0$ & $<4.0$ & - \\
\hline
\end{tabular}




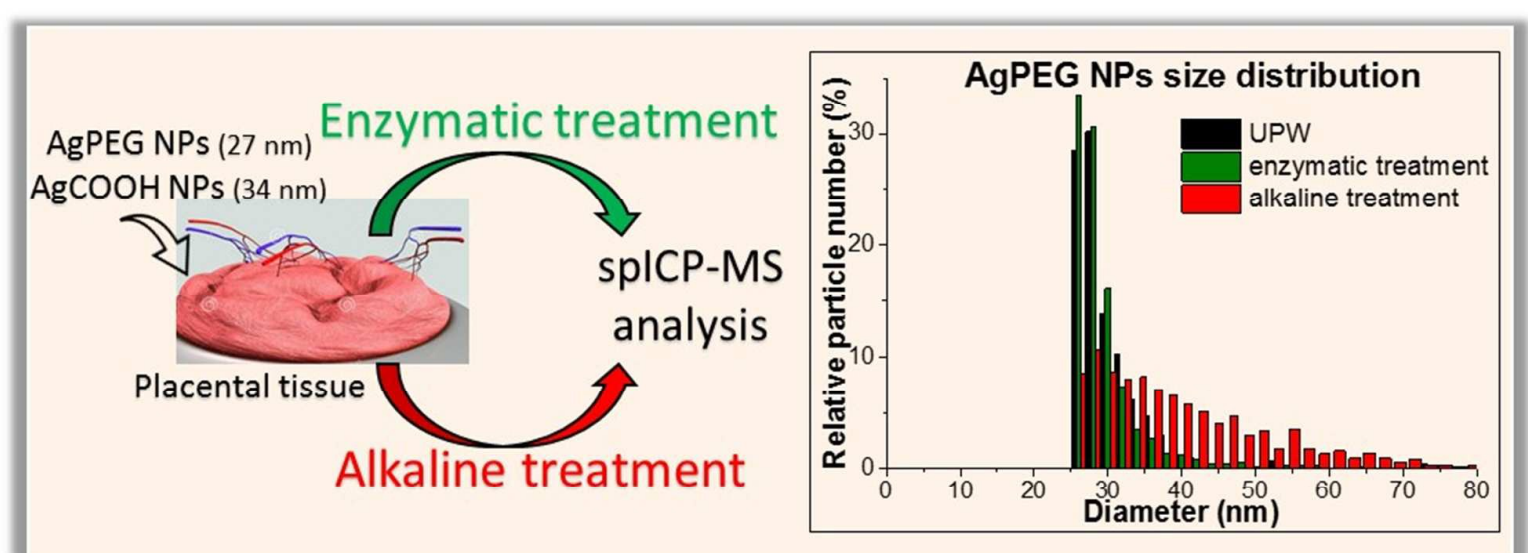


Fig. 1

\section{Ex vivo human placental perfusion experiment}

AgPEg NPs AgCOONa NPs Ag+ |AgPEG NPs AgCOONa NPs Ag+

$26.8 \mathrm{mg} / \mathrm{kg}_{\text {tissue }} \quad 66.0 \mathrm{mg} / \mathrm{kg}_{\text {tissue }} \quad 2 \mathrm{mg} / \mathrm{kg}_{\text {tissue }} \quad 13.4 \mathrm{mg} / \mathrm{L} \quad 32.9 \mathrm{mg} / \mathrm{L} \quad 1 \mathrm{mg} / \mathrm{L}$ $\downarrow$

$\downarrow$ $\downarrow$

$100 \mathrm{mg}$ tissue homogenate (dilution factor of 2) $\downarrow$ Enzymatic/alkaline treatment
$200 \mathrm{mg}$ tissue homogenate after $6 \mathrm{~h}$ of perfusion

- AgPEG NPs (12.48 mg/L)

AgCOONa NPs (39.26 mg/L)

$\mathrm{Ag}+(1 \mathrm{mg} / \mathrm{L})$

splCP-MS $\quad$ conventional ICP-MS


3

4

5

6

7

8

9

10

11

12

13

14

iิ5

ब 6

97

当 8

ติ9

so

1

32

23

24

举

6

8

39

30

1

32

3

4

5

36

37

39

40

41

42

43

44

45

46

47

48

49

50

51

52

53

54

55

56

57

58

59

60

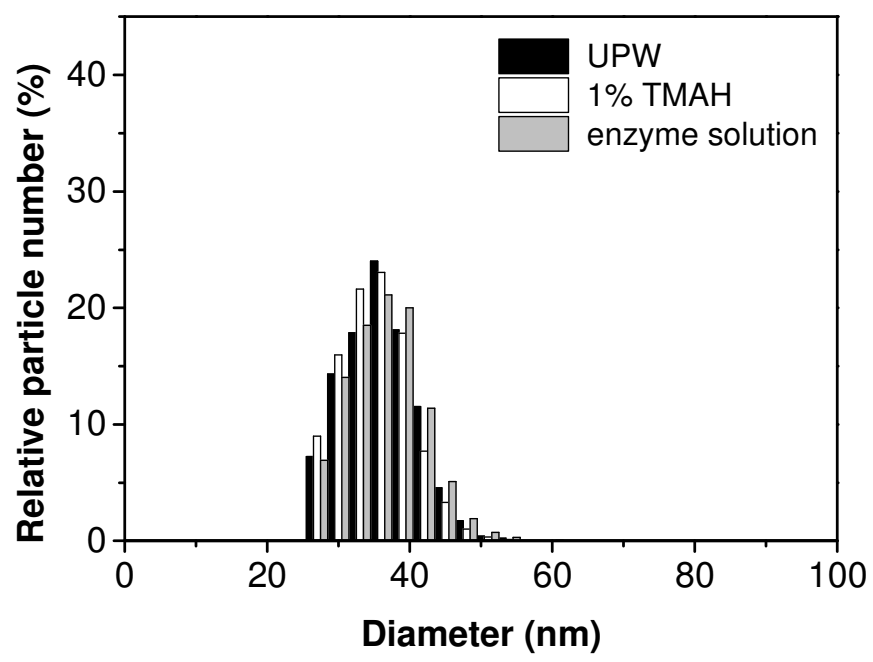

Fig. 2 

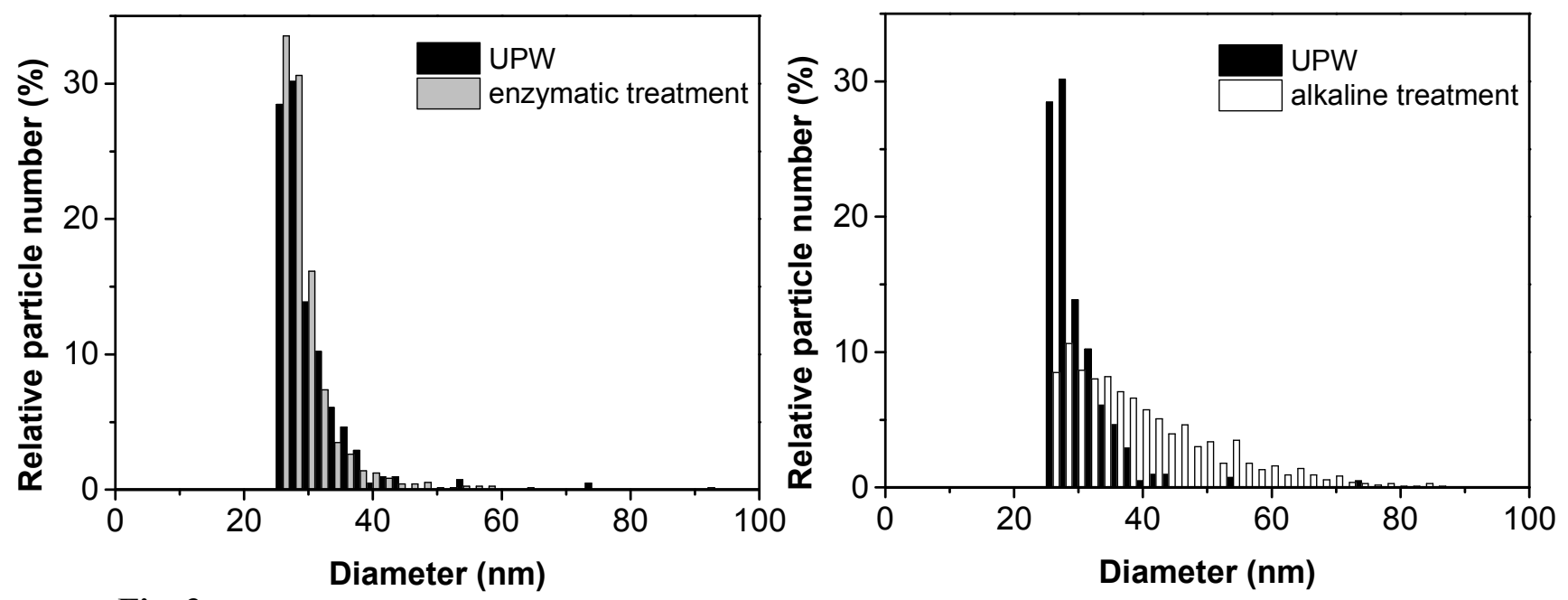

Fig. 3 


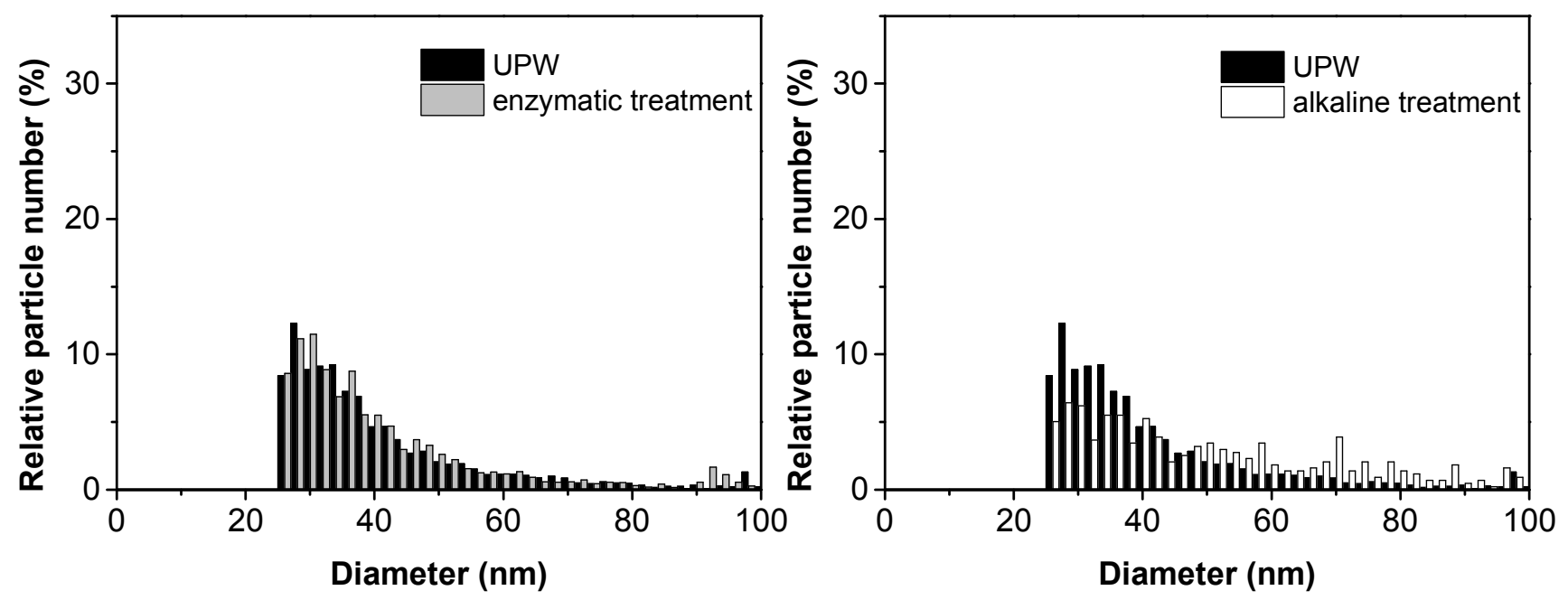

Fig. 4 